Original article

\title{
Perception, preparedness and response of health care personals towards COVID-19 pandemic in Azad Jammu \& Kashmir, Pakistan: A cross sectional interview based study
}

\author{
Muhammad Faraz Khan ${ }^{\text {a }}$, Majid Mahmood ${ }^{\text {b, }}$, Muhammad Naseem Hasrat ${ }^{c}$, Bilal Javed ${ }^{\text {d, }}$ \\ Ozan Javed $^{\mathrm{e}}$
}

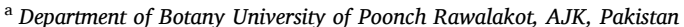

${ }^{\mathrm{b}}$ Department of Zoology, University of Poonch Rawalakot, AJK, Pakistan

c Shaikh Khalifa bin Zayed Al Nahyan DHQ Hospital, Rawalakot, AJK, Pakistan

${ }^{\mathrm{d}}$ Department of Botany, PMAS-Arid Agriculture University, Rawalpindi, Punjab, Pakistan

${ }^{\text {e }}$ Saidu Medical College, Swat, KPK, Pakistan

\section{A R T I C L E I N F O}

\section{Keywords:}

COVID-19

Corona-virus

AJK

Pakistan

Pandemic

\begin{abstract}
A B S T R A C T
Objective: To assess the state of knowledge, perception, preparedness and satisfaction level of health care personals (HCPs) in Azad Jammu \& Kashmir (AJK) towards COVID-19.

Study design: It was cross sectional survey conducted by personal interviews.

Methodology: The study was conducted by interviewing 302 HCPs from 7 major district headquarter hospitals of AJK from May to September 2020. The questionnaire included 29 questions about demography, perception, training, preparedness, knowledge and awareness of HCPs about COVID-19. The data was encoded and analyzed statistically.

Results: Majority of the respondents (78.5\%) believed that corona-virus is a serious health threat. However, $10.6 \%$ perceived it as a bio-weapon and $4.3 \%$ as not dangerous. About $10 \%$ of doctors were not considering it very dangerous compared to $1 \%$ of paramedics and $2.5 \%$ of the supporting staff $(P=0.003)$. About $55 \%$ of the respondents showed confidence of the steps taken by government for prevention of COVID-19 while $45 \%$ had an opposite view. More than $70 \%$ of the participants had no formal training and the ratio of trained personals was significantly higher (0.018) in paramedical staff (33\%) than doctors (15\%). About 53\% of the respondents were not satisfied with the provision of PPEs and 64\% were not satisfied with their work and wages situation. Majority of the respondents (97\%) were observed to follow the protocols for personal protection.

Conclusion: Majority of HCPs perceive covid-19 as a serious health concern. However, most of the HCPs are neither well trained for the current pandemic nor fully satisfied about personal protection, work load, and wages.
\end{abstract}

\section{Introduction}

As of November 2020, corona virus disease 2019 (COVID-19) has been confirmed in $57,882,183$ people with $1,377,395$ deaths worldwide, carrying a mortality rate of approximately $2.38 \% .{ }^{1}$ The dreadful aspect of COVID-19 remained its ability to spread at an unprecedented scale making it a pandemic in mere couple of months. It is now a globally accepted fact that human behavior towards this virus determines primarily the degree of its prevalence and concomitant loss to the humankind. This becomes even more significant when it comes to the perception and response of health care personnel (HCPs). Owing to this fact center for disease control and prevention (CDC), as national health protection agency of the United States issues and constantly updates the safety guidelines for HCPs across the world. ${ }^{2}$

Since outbreak of COVID-19 previously known as 2019-nCoV during fall 2019, scientific community remained focused to improve our understanding of the disease and possible cures. ${ }^{3,4}$ From genome analysis and potential avenues for development of vaccines to symptoms and epidemiology, science is putting its best to rescue the humanity. So for, the disease is characterized by mild to acute respiratory illness with

\footnotetext{
* Corresponding author. Department of Zoology, University of Poonch Rawalakot, AJK, Pakistan.

E-mail addresses: mfarazkhan@upr.edu.pk (M.F. Khan), drmajid@upr.edu.pk (M. Mahmood), naseemhasrat@gmail.com (M.N. Hasrat), javedbilal87@gmail.com (B. Javed), ozan.javed678@gmail.com (O. Javed).
} 
fever, cough and breathing distress. Severe disease onset particularly in cases where patients are aged or suffering from any other underlying illness results in death due to massive alveolar damage and respiratory failure. ${ }^{4,5}$ Till now, person-to-person transmission via direct contact or through droplets spread by coughing or sneezing from an infected individual tops the list of viral spread routes. ${ }^{6}$ Transmission of virus from symptomatic healthcare personals (HCPs) to family members is widely reported meanwhile few reports of asymptomatic individuals transmitting the disease are also published. ${ }^{7}$

Despite of a universal consensus of scientific community on existence, virulence and ultimate impact of corona virus on human health, there is still a gap in right perception towards myths and facts about COVID-19. ${ }^{8}$ HCPs are frontline defenders in ongoing COVID-19 pandemic therefore, misleading perception and inappropriate attitudes among HCPs is a serious concern. As it can directly influence malpractices while dealing COVID-19 patients leading to delayed diagnosis, poor infection control, and disease transmission within and outside healthcare facilities. ${ }^{9}$ As of March 2020, up to $4 \%$ of total COVID-19 cases were reported to have occurred in HCPs. ${ }^{10}$ With the advent of COVID-19 in Pakistan, medical workers have been under physical and psychological stress including high risk of infection. ${ }^{11}$ Early evidence suggests that HCPs in Pakistan make up to $20 \%$ of the infected population. Major factors included lack of understanding, inadequate use and availability of personal protective equipment (PPE), and psychological stress. $^{12}$

Azad Jammu \& Kashmir is an autonomous state inhabited by approximately 4.8 million people administered by federal government of Pakistan (Fig. 1). Due to geographical remoteness, and timely decision of the state government first wave of corona virus was successfully managed by apparently weak healthcare system that hardly comprises of three major and 4 supporting hospital in entire state. According to media reports the total number of COVID-19 patients was just 107 in AJK on May 16, 2020 with one reported death. ${ }^{13}$ However, repeating incidences of bulk infection of HCPs particularly the doctors raised questions about the perceptions and overall attitude towards corona virus. As of August 29, 2020, a total of 86 doctors, 13 nurses and 100 other HCPs were affected by COVID-19. ${ }^{14}$ It is therefore important to assess readiness and response potential of HCPs in a state which is vulnerable to explosive epidemic situation owing to massive and seemingly ill monitored to and fro movement of locals to big cities of Pakistan. Moreover, a 1/5th of the state residents are working as expatriates in Middle-East, Europe and North America who are potential careers for the virus. Objectives of this study were: 1 - To assess current state of knowledge, perception and preparedness of HCPs to combat ongoing pandemic and 2- To gauge overall combat depth of state healthcare infrastructure by analyzing skillfulness and job satisfaction of HCPs.

\section{Materials and methods}

\subsection{Study design and setting}

The study was a cross sectional survey conducted by using a structured questionnaire randomly from different health care workers of seven (7) district head quarter (DHQ) hospitals of Azad Jammu and Kashmir i.e. DHQ hospital Muzaffarabad, DHQ hospital Bagh, DHQ hospital Rawalakot, DHQ hospital Palandari, DHQ hospital Kotli, DHQ hospital Mirpur and DHQ hospital Bhimber, covering entire healthcare network of the state (Fig. 1). A total of 302 health care workers participated in the survey and responded to the questionnaire with their consent. The questionnaire was prepared following the complete guidelines of WHO, published recently. ${ }^{15}$ The respondents included 127 representatives of doctors, 135 of paramedical staff and 40 of other hospital staff. Among "others", the supporting staff not having any interaction with the patients was excluded from the study while the respondents who provided redundant information or picked more than one option in the questionnaire were also excluded from the study.

\subsection{Data collection}

Besides questions related to demographic information (age, gender and profession), the survey form included 26 different questions about awareness, preparedness and personal thoughts of the participants about COVID 19. Respondents were also asked about personal protection and training of the workers, medical care of the patients, level of job satisfaction during COVID 19, and the behavior of health care workers towards COVID-19. The questionnaire had multiple choice questions designed according to "survey tools and guidance" by WHO, regional office for Europe. A focal person was selected from each of the 7 hospitals and the survey form was sent to him/her by post following all possible SOPs to prevent the transmission of corona virus. In all hospitals, the respondents were randomly selected following the SOPs and then returned by post.

\subsection{Data analysis}

A data sheet including 29 columns was prepared in MS Excel and then data was encoded and transferred to statistical software. Frequencies and percentages of all answers were calculated for each question separately. Pearson's Chi square test was performed to check the significance of differences in answers of respondents from different categories, and to compare the answer frequencies between gender, profession and different age groups of the respondents where appropriate and needed. A value of $P$ less than 0.05 was considered as significant. Statistical Package for Social Sciences (SPSS) version 16 was used for all analyses.

\subsection{Ethical approval and patient's consent}

The ethical approval for the study was obtained by "Human and animal ethics committee, university of Poonch Rawalakot" as well as from the ethical committee of Shaikh Khalifa bin Zayed Al Nahyan DHQ Hospital, Rawalakot, AJK. A written informed consent was signed by all participants of the study.

\section{Results}

\subsection{Study participants}

The study was a real survey included a total of 302 healthcare personals from seven (7) major hospitals (DHQ hospitals) of AJK. Study participants included 127 (42.1\%) doctors, 135 (44.7\%) paramedical staff and $40(13.2 \%)$ non medical hospital workers like clerical persons, administrative staff and other supporting staff personals (Table 1). A total of $161(53.3 \%)$ study participants were male while $141(46.7 \%)$ were female. Majority of the respondents $(86.4 \%)$ were in the age range of 26-60 years, while $10.6 \%$ (32) were below or equal to 25 years of age and only $3 \%$ (9) were above the age of 60 years (Table 1; Table 2).

\subsection{Questionnaire}

The questionnaire had a total of 29 columns including 26 questions on the study and 3 columns for gender, age and occupation. The questions were addressing the knowledge and perception about COVID 19, its transmission, its control strategies, the behavior of participants about the COVID 19, available facilities at hospitals of AJK, personal protection equipments availability, personal training and preparedness of the participants regarding pandemics in general and COVID 19 in particular, satisfaction of the participants about wages and workload during current situation, and the precautionary measures while working with COVID 19 patients. 


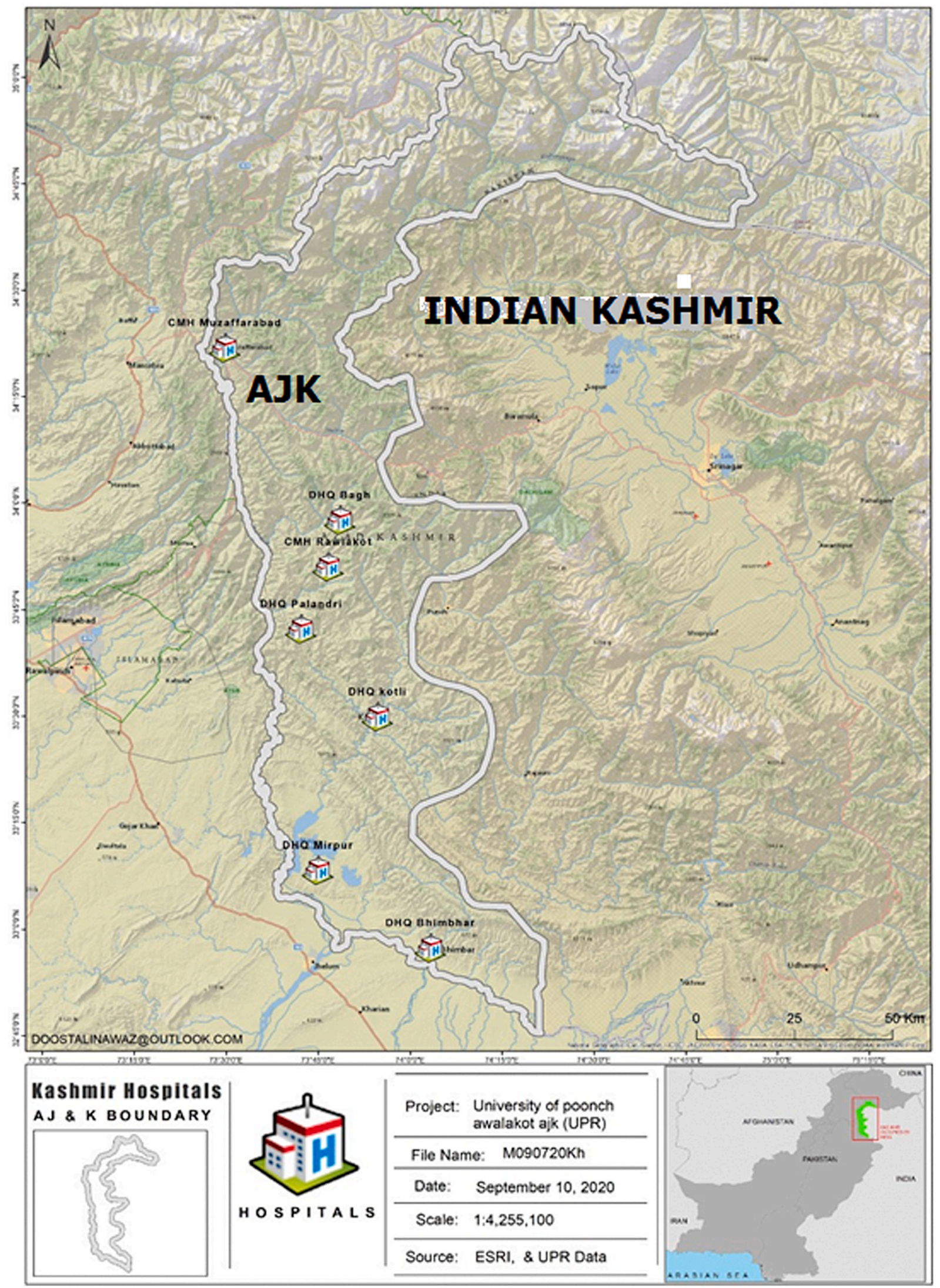

Fig. 1. Map showing the study area with all study centers. 
Table 1

Demographic data of the participants.

\begin{tabular}{|c|c|c|c|c|c|}
\hline & Category & Doctor & Paramedics & Others & Total \\
\hline \multirow[t]{2}{*}{ Gender } & Male & $\begin{array}{l}69 \\
(54.3 \%)\end{array}$ & $81(60 \%)$ & $\begin{array}{l}11 \\
(27.5 \%)\end{array}$ & $\begin{array}{l}161 \\
(53.3 \%)\end{array}$ \\
\hline & Female & $\begin{array}{l}58 \\
(45.7 \%)\end{array}$ & $54(40 \%)$ & $\begin{array}{l}29 \\
(72.5 \%)\end{array}$ & $\begin{array}{l}141 \\
(46.7 \%)\end{array}$ \\
\hline \multirow[t]{3}{*}{$\begin{array}{l}\text { Age Group } \\
\text { (Years) }\end{array}$} & $<26$ & $\begin{array}{l}13 \\
(10.2 \%)\end{array}$ & $18(13.3 \%)$ & $1(2.5 \%)$ & $\begin{array}{l}32 \\
(10.6 \%)\end{array}$ \\
\hline & $26-60$ & $\begin{array}{l}114 \\
(89.8 \%)\end{array}$ & $\begin{array}{l}109 \\
(80.8 \%)\end{array}$ & $\begin{array}{l}38 \\
(95.0 \%)\end{array}$ & $\begin{array}{l}261 \\
(86.4 \%)\end{array}$ \\
\hline & $>60$ & $0(0.0 \%)$ & $8(5.9 \%)$ & $1(2.5 \%)$ & $9(3.0 \%)$ \\
\hline Total & & $\begin{array}{l}127 \\
(42.1 \%)\end{array}$ & $\begin{array}{l}135 \\
(44.7 \%)\end{array}$ & $\begin{array}{l}40 \\
(13.2 \%)\end{array}$ & 302 \\
\hline
\end{tabular}

Table 2

Comparison of percentages of responses to different questions among three categories of HCPs.

\begin{tabular}{|c|c|c|c|c|c|}
\hline & & Doctor & Paramedics & Others & $\begin{array}{l}P \\
\text { Value }\end{array}$ \\
\hline \multirow[t]{3}{*}{ Training } & Yes & $\begin{array}{l}19 \\
(15 \%)\end{array}$ & $45(33 \%)$ & $\begin{array}{l}15 \\
(37.5 \%)\end{array}$ & 0.018 \\
\hline & No & $\begin{array}{l}86 \\
(68 \%)\end{array}$ & $68(50 \%)$ & $\begin{array}{l}16 \\
(40 \%)\end{array}$ & \\
\hline & NA & $\begin{array}{l}22 \\
(17 \%)\end{array}$ & $22(16 \%)$ & $\begin{array}{l}9 \\
(22.5 \%)\end{array}$ & \\
\hline \multirow[t]{3}{*}{ PPES } & Yes & $\begin{array}{l}63 \\
(49.6 \%)\end{array}$ & $53(39.3)$ & $24(60)$ & 0.356 \\
\hline & No & $\begin{array}{l}62 \\
(48.8)\end{array}$ & $80(59.3)$ & $16(40)$ & \\
\hline & NA & $2(1.6)$ & $2(1.4)$ & 0 & \\
\hline \multirow[t]{4}{*}{$\begin{array}{l}\text { Awareness \& } \\
\text { Preparedness }\end{array}$} & $A \& P$ & $\begin{array}{l}29 \\
(23.4)\end{array}$ & $36(27.5)$ & $14(35)$ & 0.436 \\
\hline & A but not $P$ & $\begin{array}{l}60 \\
(48.4)\end{array}$ & $49(37.4)$ & $\begin{array}{l}17 \\
(42.5)\end{array}$ & \\
\hline & None & $\begin{array}{l}13 \\
(10.5)\end{array}$ & 15 (11.4) & 5 (12.5) & \\
\hline & Not Sure & $\begin{array}{l}22 \\
(17.7)\end{array}$ & 31 (23.6) & $4(10)$ & \\
\hline \multirow[t]{3}{*}{$\begin{array}{l}\text { Source of } \\
\text { Information }\end{array}$} & Social Media & $\begin{array}{l}21 \\
(17.8)\end{array}$ & $5(3.8)$ & $4(11.1)$ & 0.000 \\
\hline & WHO \& CDC & $\begin{array}{l}80 \\
(67.8)\end{array}$ & $64(48.8)$ & $\begin{array}{l}20 \\
(55.6)\end{array}$ & \\
\hline & Institutional & $\begin{array}{l}17 \\
(8.14)\end{array}$ & $62(47.3)$ & $\begin{array}{l}12 \\
(33.3)\end{array}$ & \\
\hline \multirow[t]{3}{*}{$\begin{array}{l}\text { Work \& Wages } \\
\text { Satisfaction }\end{array}$} & Satisfied & $\begin{array}{l}20 \\
(16.4)\end{array}$ & $21(15.8)$ & $10(25)$ & 0.113 \\
\hline & Not satisfied & $\begin{array}{l}81 \\
(66.4)\end{array}$ & $86(64.7)$ & $\begin{array}{l}27 \\
(67.5)\end{array}$ & \\
\hline & Don't know & $\begin{array}{l}21 \\
(17.2)\end{array}$ & $26(19.5)$ & $3(7.5)$ & \\
\hline \multirow{2}{*}{$\begin{array}{l}\text { Personal Views } \\
\text { (Knowledge \& } \\
\text { Perception) }\end{array}$} & $\begin{array}{l}\text { Not } \\
\text { Dangerous }\end{array}$ & $12(9.8)$ & $1(0.8)$ & $1(2.5)$ & 0.003 \\
\hline & $\begin{array}{l}\text { Very } \\
\text { Dangerous } \\
\text { Bio-weapon }\end{array}$ & $\begin{array}{l}101 \\
(82.1) \\
10(8.1)\end{array}$ & $\begin{array}{l}103(85.8) \\
16(13.3)\end{array}$ & $\begin{array}{l}33 \\
(82.5) \\
6(15)\end{array}$ & \\
\hline
\end{tabular}

\subsection{Perception and knowledge of HCPs about COVID-19}

In the questionnaire, eight (8) questions were addressing different aspects of perception, knowledge and behavior of the respondents about COVID-19. About $93.7 \%$ of the participants responded to the questions on knowledge and perceptions about COVID 19. Majority of the respondents $(78.5 \%)$ believed that corona virus is very dangerous and a serious public health threat. However, $10.6 \%$ perceived it as a bioweapon and $4.3 \%$ of the respondents thought that it is not as dangerous as portrayed by media and public health agencies. A significant difference was observed among the views of different categories of health care workers $(P=0.003)$. Interestingly, about $10 \%$ of doctors were not considering it as very dangerous, compared to $1 \%$ of paramedics and $2.5 \%$ of the supporting staff (Table 2). Perception of corona virus as a bio-weapon was higher in supporting staff $(15 \%)$ and paramedics $(13 \%)$ as compared to doctors ( $8 \%)$. The perception of corona virus as a deadly and highly contagious pathogen had a fear factor as well where $75.5 \%$ of HCPs had apprehensions of carrying the infection from the hospital to their family members. A small number of respondents (14.2\%) however, did not show significant fear of corona virus while $8 \%$ had a moderate fear. The fear factor was associated with the perception of being at higher risk of getting infected inside the hospital setting as $82 \%$ of participants were thinking that the risk of infection is higher inside the hospital while $7 \%$ had an opposite perception and $6 \%$ considered the risk as equal in and outside the hospital.

The difference in knowledge and perception of different categories of HCPs can be linked with the source of information they follow generally. Highly significant difference was observed in the source of information among different categories of workers $(P=0.000)$. Around $68 \%$ of doctors were preferred the guidelines of WHO/CDC about COVID-19 as compared to $56 \%$ of supporting staff and $49 \%$ of the paramedics (Table 2). Paramedics, on the other hand were relying more (47\%) on institutional instructions and standard operating procedures, whereas, an alarmingly low number of doctors (8\%) were recorded to prefer the institutional instructions for knowledge and updates about corona virus (Table 2).

Majority of the health care personals (55\%) showed confidence of the steps taken by government for prevention of COVID-19 while about $45 \%$ had a view that the steps taken by government are not enough for prevention. In this regard, about $96 \%$ of the responders were in favor of quarantine policy of the government while only about $4 \%$ had contrasting views.

When compared between male and female, a significant difference $(P$ $=0.047$ ) was found in the views and perception about COVID-19 as about $89 \%$ of the male HCPs had a view that corona virus is very dangerous as compared to $77 \%$ of the female having this view, while $17 \%$ of the female considered it as a bio-weapon than only $6 \%$ of the male HCPs (Table 2). Moreover, the source of information relied upon for COVID-19 was also found to be significantly different between the genders $(P=0.000)$. More than $16 \%$ of the female relied upon social media as compared to only about $5 \%$ of male while $69.5 \%$ of the male were following WHO/CDC compared to $44 \%$ of female HCPs (Table 3 ).

Table 3

Gender wise comparison of responses to different questions.

\begin{tabular}{|c|c|c|c|c|}
\hline & & Male & Female & $P$ Value \\
\hline \multirow[t]{4}{*}{ Personal Views } & Not Dangerous & $7(4.7)$ & $7(5.3)$ & 0.047 \\
\hline & Very & 134 & 103 & \\
\hline & Dangerous & (89.3) & $(77.4)$ & \\
\hline & Bio-weapon & $9(6.0)$ & $23(17.3)$ & \\
\hline \multirow[t]{3}{*}{ Training } & Yes & $56(35.2)$ & $66(47.8)$ & 0.027 \\
\hline & No & $\begin{array}{l}100 \\
(62.9)\end{array}$ & $70(50.7)$ & \\
\hline & NA & $3(1.9)$ & $2(1.5)$ & \\
\hline \multirow[t]{3}{*}{ PPEs } & Yes & $70(43.5)$ & $70(49.6)$ & 0.635 \\
\hline & No & $88(54.7)$ & 69 (48.9) & \\
\hline & NA & $3(1.8)$ & $2(1.4)$ & \\
\hline Awareness \& & $A \& P$ & $49(30.4)$ & $30(21.3)$ & 0.002 \\
\hline \multirow[t]{3}{*}{ Preparedness } & A but not $P$ & 53 (32.9) & $73(51.8)$ & \\
\hline & None & $16(9.9)$ & $17(12.1)$ & \\
\hline & Not Sure & $43(26.7)$ & $21(14.9)$ & \\
\hline \multirow[t]{3}{*}{ Source of Information } & Social Media & $8(5.3)$ & $22(16.4)$ & 0.000 \\
\hline & WHO \& CDC & $\begin{array}{l}105 \\
(69.5)\end{array}$ & $59(44.0)$ & \\
\hline & Institutional & $38(25.2)$ & $53(39.6)$ & \\
\hline \multirow{3}{*}{$\begin{array}{l}\text { Work \& wages } \\
\text { satisfaction }\end{array}$} & Satisfied & $32(19.9)$ & $19(13.5)$ & 0.000 \\
\hline & Not satisfied & $87(54.0)$ & $\begin{array}{l}107 \\
(75.9)\end{array}$ & \\
\hline & Don't know & $42(26.1)$ & $15(10.6)$ & \\
\hline
\end{tabular}




\subsection{Training and preparedness}

To evaluate the status of training and preparedness of the HCPs for an outbreak like COVID-19, there were seven (7) questions in the current study. More than $70 \%$ of the participants had no formal training for working in a pandemic situation and hence they were not sufficiently prepared for current COVID-19 outbreak, while only about $26 \%$ of the HCPs were sufficiently trained. Moreover, the ratio of trained personals was found to be significantly higher (0.018) in paramedical staff (33\%) as compared to the ratio of trained doctors (15\%) in the current study (Table 2).

As far the personal protective equipment (PPE) for the situation is concerned, $53 \%$ of the respondents were reported to not have full PPEs while $47 \%$ were satisfied with the provision of PPEs by the government although $78 \%$ of the respondents were somehow trained about using and discarding the PPEs. About $64 \%$ of the respondents had access to incineration facility in hospital setting while $34 \%$ did not have it. Moreover, it was noted that all hospitals in the region either have no incinerator or it is not in working condition. However, $22 \%$ of the respondents were not aware of proper use of PPEs with particular reference to COVID-19. This has led to an overall sense of dissatisfaction toward measures and policies of the government as $58 \%$ of the respondents showed serious concerns over arrangements made by the healthcare authorities to combat the epidemic.

As far the previous training to combat such an outbreak is concerned, significantly higher $(P=0.027)$ number of female $(47.8 \%)$ were trained than male $(35.2 \%)$ while $50.7 \%$ female HCPs and $62.9 \%$ male HCPs stated that they have no training of such outbreak (Table 2). In the response to the question about awareness and preparedness, $30.4 \%$ of the male HCPs answered that they are aware and prepared for the situation compared to $21.3 \%$ of female while about $33 \%$ of male were found well aware but not prepared for handling of the outbreak as compared to about $52 \%$ of the female HCPs (Table 3 ).

\subsection{Prevention and control strategies}

Except three percent of the respondents, all others were observed to follow the protocols for personal protection to a greater extent where $61 \%$ of the respondents were actually using recommended PPEs for COVID-19 while another $36 \%$ were maintaining a considerable level of personal protection by using gloves, masks and practicing social distancing while working in designated COVID-19 facilities. During survey, it was reported that fulfilling personal protective measures was considerably difficult as $54 \%$ of the respondents expressed that maintaining social distance is not easy to comply for them while another $36 \%$ had a view that recommended set of protective measures is not completely applicable for them.

A vast majority of the respondents (94.5\%) were found satisfied by the way their hospital was being disinfected, particularly the areas with COVID-19 patients. They were also confident on following the SOPs for transfer of patients to the hospital and discharge of recovered patients or dealing with the dead bodies of COVID-19 patients if in case.

\subsection{Work and wage satisfaction}

An overall sense of unrest and panic was observed among HCPs during the survey. Majority of the respondents (64\%) were not satisfied with their duty hours, working conditions, workload, and their wages during the COVID-19 outbreak while only $17 \%$ of the respondents showed satisfaction towards their work and wage, a considerable fraction of respondents (20\%) were hesitant to answer the question. This dissatisfaction status was statistically equal $(P=0.113)$ in all three categories of respondents (Table 2). However, there was a breach between doctors and other staff including paramedics on the behavior of doctors and administrators as $29 \%$ of the respondents (mostly other than doctors) showed a discontent towards the attitude of doctors and administration. The perception of dissatisfaction extends beyond hospital management as only $37 \%$ of the respondents were fully satisfied by government while the remaining bulk was either partially satisfied or not satisfied at all.

In comparison between genders, it was found that the level of dissatisfaction with work and wages is significantly higher $(P=0.000)$ in female than male HCPs of AJK as about $76 \%$ of the female HCPs showed dissatisfaction compared to $54 \%$ of the male HCPs while only $13.5 \%$ of female were found satisfied compared to $19.9 \%$ of males. A considerable number of male $(26.1 \%)$ and female $(10.6 \%)$ did not respond to the question of satisfaction however (Table 3 ).

\section{Discussion}

Since the onset of covid-19 in Wuhan, China back in fall, 2019 the efficiency of healthcare system of a country remained a key factor in national response towards the pandemic. Many of the western countries with apparently advanced and well equipped epidemic control system collapsed badly. On contrary, a good number of south East Asian nations managed not only to control the damage but successfully took this novel virus under control. Performance of national/state health machinery can better be gauged if bisected into two basic components 1- infrastructure and supplies of emergency response equipments and 2- perception, preparedness and response of healthcare professionals. In case of third world countries like Pakistan fragility of healthcare infrastructure is almost obvious and financial constraints seriously limit the capacity of governments to maintain optimum supply of equipment. Therefore one has to rely largely on the second component as for as resilience against any such pandemic has to be assessed.

Herein we aimed to conduct a real time survey using a structured questionnaire in all seven major hospital settings of the state of Azad Jammu and Kashmir. The questionnaire was designed to acquire statistically robust and reproducible data. We split our important findings in a priority order as; perception and knowledge, training of HCWs, control strategies and job satisfaction during this particular scenario. Unlike previous epidemics in recent past, the basic perception of general public about nature of Corona virus never remained undivided. Conspiracy theories ranged from $5 \mathrm{G}$ chip to bioengineered weapon and lot more. Being part of a conservative society, HCWs in AJK were likely to be affected by myths and pseudoscience thereby jeopardizing their ability to respond and scientific understanding of novel corona virus.

Majority of the respondents (78.5\%) believed that corona virus is very dangerous and a serious public health concern. However, $10.6 \%$ perceived it as a bio-weapon and $4.3 \%$ of the respondents thought that it is not as dangerous as hyped by media and public health agencies. This was encouraging as gravity of the danger was well perceived and that seems evident in the way state of AJK remained one of the least affected unit of Pakistan during first wave of the pandemic. The number of COVID-19 patients was just 107 in AJK on May 16, 2020 with only one death. ${ }^{13}$ However, significant difference was observed among the views of doctors and paramedics as about $10 \%$ of doctors were not considering it as dangerous as compared to only $1 \%$ of paramedics. Rate of infection and deaths in AJK is directly proportional to the difference in perception and level of precautions. As of August 2020, the total no of HCPs infected in entire state was 140 with majority of doctors and paramedics. ${ }^{14}$

In present study, although the most relied sources of information were global health advisors such as WHO and CDC, a reasonable number of workers relied upon social media and other local sources of information. This is generally fine and precedential but, when we look it up keenly, doctors were following the guidelines of WHO/CDC or institutional SOPs. But reliance of other HCPs on social media based information was significantly high. Questions were also asked to evaluate the level and quality of training the HCPs of AJK have, which revealed the fact that significantly lower percentage of doctors are trained previously for any epidemic situation compared to paramedics and other hospital staff (15\%:33\%:37\% respectively). Overall, less than 30\% of the HCPs 
are trained to work in epidemic situation like that of Covid-19. In continuation, preparedness and response potential was also less than $30 \%$ which also questions the morale and mental health status of the HCPs. According to a recent study, fear of carrying disease to families and job stress is negatively affecting the response capacity of HCPs in Pakistan. ${ }^{16}$ Therefore, measure for training and capacity building of medical professionals can significantly alleviate the impacts of deadly virus. $^{17}$

A very important aspect in management of any pandemic generally and COVID-19 especially is the job satisfaction of HCPs as frontline personals. That includes comfortable workplace environmental, job security and wages. Level of satisfaction, if not achieved at any level, negatively influence the working ability of the workers in any institution. Low level of satisfaction leads to depression, anxiety and consequently limits work efficiency as reported already from Pakistan. ${ }^{15-18}$ In the current study, only about $19 \%$ of the total hospital workers including doctors were fully satisfied while the majority (about 66\%) were not satisfied at all and the level of satisfaction was equally low in all three groups of the workers. Similar observations were also reported recently from other nearby areas of Pakistan and Bangladesh. ${ }^{15-18}$ The satisfaction level of workers can be enhanced through provision of better PPEs, increased human resource, better infrastructure, and more than sufficient funding to the hospitals which is a bit difficult in low or middle income developing countries like Pakistan and Bangladesh.

\section{Conclusion}

The study concludes that majority of HCPs of AJK perceive covid-19 as a serious public health concern. As of now, the pandemic is well managed in the state that implies courageous and out of capacity performance of HCPs. However, most of the HCPs including doctors are neither well trained and prepared for the current pandemic, nor they are fully satisfied about personal protection, their work load, and wages. A significant disparity was seen between doctors and other HCPs regarding knowledge and perception of COVID-19, reliance on sources they use for relevant information, and extent of previous training. Moreover, confusions about the nature and seriousness of outbreak are still there which impair the response potential of HCPs. To enhance combat efficacy of state healthcare system, measures regarding awareness, training, and capacity building are merited. Supply chain management of PPEs and supportive care medicine should be closely monitored, so as to augment the trust of HCPs on their organization.

\subsection{Study limitations}

The sample size in the survey is relatively small as to the recommended requirements. It was because of the fact that the total number of health care workers in all seven designated hospital settings of the study area is hardly double of the sample included in the study. Keeping this fact in mind, about $50 \%$ of the total population was selected as sample for the study.

\section{Authors Contribution}

MFK and MM conceived the idea. BJ and OJ prepared the questionnaire. MNH managed the survey and data collection. BJ and OJ organized the data. MM analyzed the data statistically and interpreted the results. MFK and MM drafted the manuscript. All authors read, reviewed, and approved the final manuscript.

\section{Funding}

No funding was received for this work.

\section{Declaration of competing interest}

No conflict of interest exists among authors.

\section{References}

1 WHO. Coronavirus Disease 2019 (COVID-19) Situation Report -52; 2020. March 12 https://www.who.int/docs/default-source/coronaviruse/20200312-sitrep-5 2-COVID-19.pdf?sfvrsn=e2bfc9c0_2.

2 CDC, Interim US Guidance for Risk Assessment and Work Restrictions for Healthcare Personnel with Potential Exposure to COVID-19.

3 Wu F, Zhao S, Yu B. A new coronavirus associated with human respiratory disease in China. Nature. 2020;579:265-269.

4 Huang C, Wang Y, Li X, et al. Clinical features of patients infected with 2019 novel coronavirus in Wuhan, China. Lancet. 2020;395:497-506.

5 Chan JFW, Yuan S, Kok KH, et al. A familial cluster of pneumonia associated with the 2019 novel coronavirus indicating person-to-person transmission: a study of a family cluster. Lancet. 2020;395:514-523.

6 Carlos WG, Dela Cruz CS, Cao B, Pasnick S, Jamil S. Novel Wuhan (2019-nCoV) corona virus. Am J Respir Crit Care Med. 2020;201(4):7-8.

7 Bai Y, Yao L, Wei T, et al. Presumed asymptomatic carrier transmission of COVID-19. J Am Med Assoc. 2020;323(14):1406-1407. https://doi.org/10.1001/ jama.2020.2565.

8 Narayana G, Pradeepkumar B, Ramaiah JD, Jayasree T, Yadav DL, Kumar BK. Knowledge, perception, and practices towards COVID-19 pandemic among general public of India: a cross-sectional survey. Current Med Res Prac. 2020;10(4):153-159. https://doi.org/10.1016/j.cmrp.2020.07.013.

9 Wahed AWY, Hefzy EM, Ahmed MI, Hamed NS. Assessment of knowledge, attitudes, and perception of health care workers regarding COVID-19, A cross-sectional study from Egypt. J Community Health. 2020;45(6):1242-1251. https://doi.org/10.1007/ s10900-020-00882-0.

10 Wu Z, McGoogan JM. Characteristics of and important lessons from the coronavirus disease 2019 (COVID-19) outbreak in China: summary of a report of 72314 cases from the Chinese Center for Disease Control and Prevention. J Am Med Assoc. 2020; 323(13):1239-1242. https://doi.org/10.1001/jama.2020.2648.

11 Rana W, Mukhtar S, Mukhtar S. Mental health of medical workers in Pakistan during the pandemic COVID-19 outbreak. Asian J Psychiatr. 2020;51. https://doi.org/ 10.1016/j.ajp.2020.102080.

12 Ali S, Noreen S, Farooq I, Bugshan A, Vohra F. Risk assessment of healthcare workers at the frontline against COVID-19. Pak J Med Sci. 2020;36(COVID19-S4).

13 Naqash T. Daily Dawn; 2020. . Accessed May 16, 2020.

14 Pakistan Case Details. Government of Pakistan; 2020. Available on http://covid.gov. $\mathrm{pk} /$.

15 World Health Organization Regional Office for Europe. Survey Tool and Guidance: Rapid, Simple, Flexible Behavioural Insights on COVID-19. 2020, 29 July 2020.

16 Urooj U, Ansari A, Siraj A, Khan S, Tariq H. Expectaions, fears and perception of doctors during COVID-19 pandemic. Pak J Med Sci. 2020;36. COVID-19-S37-S42.

17 Mumu SB, Aktar MN, Nahar Z, Sharmin S, Mostaid MS. Medical doctors awareness, perception, and attitude towards COVID-19 in Bangladesh: a cross sectional study. medRxiv. 2020;5(14):20101659. https://doi.org/10.1101/2020.05.14.20101659.

18 Amin F, Sharif S, Saeed R, Durrani N, Jilani D. COVID-19 pandemic- knowledge, perception, anxiety and depression among frontline doctors of Pakistan. BMC Psychiatr. 2020;20:459. https://doi.org/10.1186/s12888-020-02864-x. 